BOOK REVIEW

\title{
GORDON BAILEY and NOGA GAYLE, Ideology: Structuring Identities in Contemporary Life. Peterborough: Broadview Press, 2003, 175 pp., $\$ 24.95$.
}

\author{
Reviewed by Pat Durish, OISE University of Toronto
}

Recently, questions concerning the nature of citizenship and democracy have been a major preoccupation for both academics and policy makers. At the level of real existing relations, this state of affairs can be attributed to the ongoing and far-reaching effects of globalization. At the level of theory, this situation can be attributed to the introduction of poststructuralist and postmodernist theoretical paradigms. These factors, as well as the growing recognition that social formations of race, class, gender and sexuality exert a determinant influence at the level of real existing relations and theory, have made it imperative that we revisit key modernist concepts such as citizenship, the nation-state, nationalism and democracy. Within academic circles these debates have not been restricted to political scientists. Theorists from a variety of disciplines have weighed in on the subject. In the context of these debates, many scholars have noted the problems associated with key elements of the modernist paradigm. However, little progress has been made towards posing workable alternatives.

In their book, Ideology: Structuring Identities in Contemporary Life, two sociologists, Gordon Bailey and Noga Gayle, weigh in on the issue of citizenship. In the context of their discussion of contemporary political relations, they draw on the theoretical traditions of Marxism, postmodernism and poststructuralism. Their conceptual framework privileges the concept of ideology and the process of identity formation. In 
this, their work brings to mind the rich tradition of theorising that has characterised the British stream of cultural studies beginning with Raymond Williams and more recently identified with the work of Stuart Hall. Bailey and Gayle's theorising is shaped by their desire to honour their political principles, as well as their disciplinary allegiance to sociology. Their commitment to a politics of difference is laudable, especially considering that much that is written in this vein has been criticised for mislaying its political principles. Bailey and Gayle's allegiance to sociology presents an equally, if not more difficult, challenge than that of maintaining the political force of their arguments.

This is a slim volume, numbering 175 pages, including a glossary of terms and a bibliography. The glossary is particularly useful as it provides clear and concise definitions of key terms that are highlighted throughout the text. The book opens with a discussion of the concept of ideology, including a brief overview of the historical evolution of the term and the various definitions that have been attributed to it over the course of its history. Bailey and Gayle's main focus is on the role that ideology plays in the everyday life of individuals, primarily as it functions to condition identities, which in turn help to secure ruling relations. Throughout the text they refer to, and attempt to illustrate, the ways that social formations of race, class, gender and sexuality intersect with each other to secure a set of social relations that delineate privilege along these same lines. The authors go on to define representation as an ideological practice and later chapters explore the role of ideology in spaces not overtly recognized as political, such as those occupied by the media, entertainment, and advertisement industries. Their intention is to trace the dialectical relationship that exists between public/private space. In their final chapter, Bailey and Gayle address the issue of citizenship and advocate for an expanded notion of the political that would encourage more creative ways for resisting domination within the plethora of sites where relations of citizenship are consolidated.

Bailey and Gayle's book is important because of their attempt to wade into the ongoing debate regarding citizenship and because they attempt to do so while maintaining their commitment to a politics of difference. In addition, the fact that they attempt to bridge the disciplinary gap that exists between political, cultural and sociological theory holds out the possibility of gaining new perspective on a debate that has suffered from a lack of forward momentum. Their book is accessibly written and the authors make liberal use of examples from everyday life in order to illustrate ideas that can often intimidate the neophyte. In general, Bailey and Gayle offer up to their readers clear and concise renderings of some of the key concepts in contemporary cultural and political theory.

The aforementioned rootedness of the authors in the discipline of sociology is both a major strength and a major weakness of the text. The authors reference the work of 
classic theorists of sociology such as C. Wright Mills, B. Singh Bolaria and K. Mannhiem, as well as more populist thinkers such as John Ralston Saul and Noam Chomsky. This diversity of sources creates an opportunity for the authors to talk across the divisions that exist between the disciplinary traditions of political and cultural studies and sociology, thereby creating the potential for us to hone our understanding of key areas of social life. However, the linkages between different ideas are not always clearly laid out in the text, with the result resembling a case of forced association, rather than cross-disciplinary communication. A good example is the juxtaposition of $\mathrm{C}$. Wright Mills' theory concerning the contextualisation of social phenomena with that of Marx's theory of dialectical materialism. The authors offer a clear, albeit very truncated, reading of these equally important ideas but the connection between the two is never made clear. I was left wondering if the authors offered Wright Mills' theory as a compliment or as a modifier to Marx.

Although its slimness makes this volume less intimidating than it otherwise might have been, the authors have tried to cover an expansive and uneven theoretical terrain in very few pages. As a result, discussions of key ideas and concepts are so brief as to appear overly simplistic. Many of the chapters appeared to be cobbled together and the ensuing discussions are frequently tangential. For example, in the course of two pages the authors introduce and discuss the concept of ideology as well as feminist arguments concerning the division of space into the public and the private. The concept of ideology is further developed in what appears as a sidebar to chapter three, which is ostensibly dedicated to issues of socialization. The discussion of the division of space suddenly reappears, unannounced, in chapters four and five. Although the ideas contained in each subsection are well articulated, the overall organization within and between the various chapters is at times problematic. Furthermore, although the decision to include examples as a mean of illustrating complex political concepts is laudable in itself, frequently the connections between the examples and the concept under discussion is not very obvious, a state of affairs that adds to the confusion rather than alleviating it.

A glaring omission in the text is the absence of any serious discussion of Antonio Gramsci's contribution to Marxism. This omission is particularly interesting considering that the authors have dedicated a section to Althusser, a theorist who was strongly influenced by Gramsci and whose rather convoluted ideas are rendered more accessible if one considers them as a refinement of Gramsci's arguments concerning the epistemological nature of ideology. Furthermore, the authors continually reference several of Gramsci's key ideas such as hegemony, civil society, and the fact that in everyday life ideology usually appears in the guise of our common sense understanding of the world. Not only do the authors make liberal use of these concepts in their work without reference to Gramsci, none of the terms are properly defined in the body of the 
text. As well, several of the key cultural theorists that the authors cite in the text, such as Stuart Hall and John Fiske, are very vocal about the heavy debt they owe to Gramsci. Considering all these factors I would think it imperative that the authors reserve some space for a discussion of Gramsci's work. Yet the only mention of Gramsci occurs in a rather lengthy quote later in the text, well after the main discussion of ideology has taken place.

The concluding chapter in which the authors offer their thoughts on how citizenship can be reconceptualised suffers from the scattered nature of the preceding chapter. The inclusion of overly long quotes, something that is a problem throughout the text, and the introduction of new theorists and concepts further undermines the thrust of their arguments. In addition, considering that they chose to frame their arguments as a contribution to theorising about citizenship, they make no attempt to connect with the considerable amount of literature that has been generated in this area. Finally, although the authors have attempted to foreground issues of race, class and gender there is little evidence to suggest that their attempts in this regard have seriously impacted their mode of analysis.

If, in fact, it was Bailey and Gayle's intention to provide sociology students with an introduction to important areas of political theory, their efforts are to be celebrated and supported. Unfortunately poor organization and conceptualization compromise what could have been a fruitful enterprise. In the end, students may be better served by some of the introductory texts that are available in the field of cultural studies such as those that have been developed by the Open University in London under the editorial leadership of Stuart Hall. 